\title{
The prone 12 o'clock position reduces ileal intubation time during colonoscopy compared to the left lateral 6 o'clock (standard) position
}

\author{
Arjuna P De Silva ${ }^{1 *}$, Ravindu S Kumarasena ${ }^{2}$, Suramya D Perera Keragala' ${ }^{1}$, Udaya Kalubowila ${ }^{2}$, Madunil Niriella ${ }^{2}$, \\ Anuradha S Dassanayake ${ }^{3}$, Arunasalam Pathmeswaran ${ }^{4}$ and $\mathrm{H}$ Janaka de Silva ${ }^{1}$
}

\begin{abstract}
Background: lleal intubation is the gold standard for a complete colonoscopy. However, despite evidence of clinical benefit ileoscopy is not always attempted due to perceived technical difficulty. Our aim was to compare time taken for ileal intubation using a new position-the prone 12 o'clock position (PP) with the standard method (left lateral 6 o'clock position-LLP).
\end{abstract}

Methods: We performed a pilot study using fluoroscopy to determine the best patient position for ileal intubation. This was the prone 12 o'clock position. Patients were colonoscoped in the left lateral position and then randomized to ileal intubation in the 6 o'clock position(LL) or the 12 o'clock (PP) position.

Results: 202 consecutive patients were referred for colonoscopy. Colonoscopy was performed on 150 patients [82 females, mean (SD) age 53 (16) years]. 75 patients were randomized for ileal intubation in the PP and 75 patients in the LLP. Overall, the ileum was successfully intubated in 145 (96\%) patients [74 (98.7\%) in the PP and71 (94.7\%) in the LLP]. The median (Interquartile Range) ileal intubation time was 12 (10) seconds in the PP and 87 (82) seconds in the LLP ( $p<0.0001$; Mann-Whitney $U$ test). The ileum was abnormal in 11 (7.5\%) patients.

Conclusions: During colonoscopy, the prone 12 o'clock position gives a more direct approach to the ileo-caecal valve and significantly reduces ileal intubation time.

Trial registration: Trial registry: Sri Lanka Clinical Trial Registry

Clinical trial registry number: SLCTR/2009/002

\section{Background}

Colonoscopy is a widely practiced procedure. Ileal intubation is widely regarded as the gold standard for evidence of complete colonoscopy [1]. However, this is not routinely attempted because of perceived technical difficulty, excess time thought to be added to the procedure or the low diagnostic yield that it was thought to provide [2]. However, there is mounting clinical evidence that ileoscopy is of clinical benefit [3]. It also important to remember that if ileoscopy is not routinely practiced, performing an ileoscopy may become difficult even when there is a definite clinical indication for doing so,

\footnotetext{
* Correspondence: apdsilva@yahoo.com

'Departments of Medicine, Faculty of Medicine, University of Kelaniya,

Ragama, Sri Lanka

Full list of author information is available at the end of the article
}

such as, when Crohn's disease or ileal tuberculosis is suspected.

Currently the position employed to intubate ileum is with the patient in the left lateral position and entering the valve at the 6 o' clock position [4]. However, we have sometimes encountered difficulty when performing ileoscopy in this position leading to extra time being taken during busy endoscopy lists. During such difficult procedures we found that placing the patient in the prone position facilitated ileal intubation.

The aim of our study was to test the hypothesis that the prone position made ileal intubation easier and quicker than the standard position that is currently used-the left lateral position.

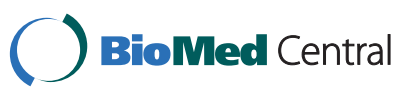

(c) 2011 De Silva et al; licensee BioMed Central Ltd. This is an Open Access article distributed under the terms of the Creative Commons Attribution License (http://creativecommons.org/licenses/by/2.0), which permits unrestricted use, distribution, and reproduction in any medium, provided the original work is properly cited. 


\section{Methods}

We first performed a pilot study on ten patients undergoing routine colonoscopy using fluoroscopy to determine the best patient position for the most direct (endon) approach to the ileo-caecal valve. Confirming our clinical impressions, the prone 12 o'clock position appeared to be the best position as this brought the tip of the colonoscope in line with the ileocaecal valve (Figure 1). This was unlike in the 6 o'clock position where the tip of the colonoscope was curved and not in the same axis (Figure 2).

We then randomized consecutive patients referred for colonoscopy to our unit between February2009 and Jan 2010 using computer generated random numbers. Patients aged between $18-80$ years and who were not pregnant were recruited after obtaining their written informed consent. They were then randomized to undergo ileoscopy either in the standard position or the prone 12 o'clock position.

All patients were given four packets of polyethylene glycol (PEG) for bowel cleansing prior to colonoscopy. All patients received pre-medication with midazolam 2.5 $\mathrm{mg}$ i.v. and pethidine $25 \mathrm{mg}$ i.v. All patients had pulse oximetry monitoring during the procedure. None of the patients were given hyoscine-n-butyl bromide. The colonoscopes used were Olympus GF Q145L models.

All colonoscopies were performed by experienced endoscopists (MAN and KVUK). The procedures were started in the left lateral position and the position changed after reaching the caecum, according to randomization. After the ileo-caecal valve was identified, ileal intubation time was standardized, and defined as the time taken for the tip of the colonoscope to be maneuvered from the mid-point of the caecum to entering the terminal ileum. This was timed by an independent observer (RSK).

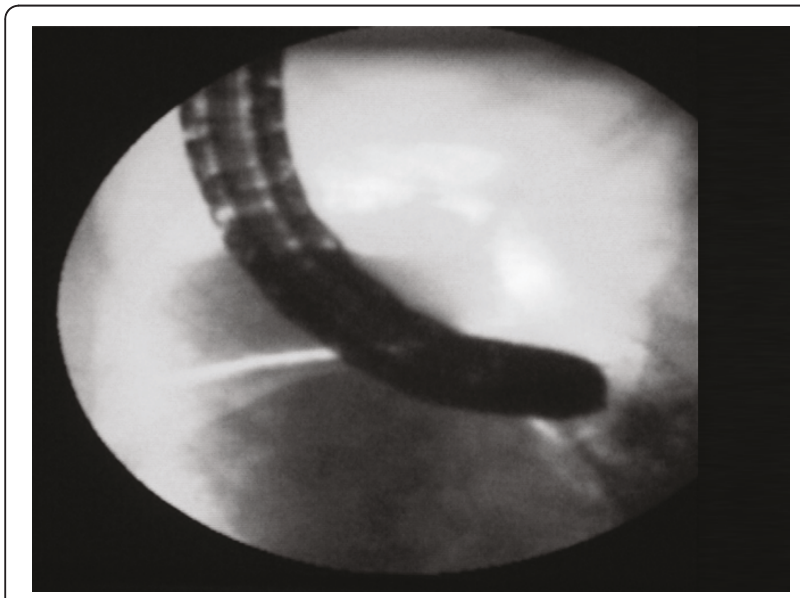

Figure 1 The 12 o'clock position.

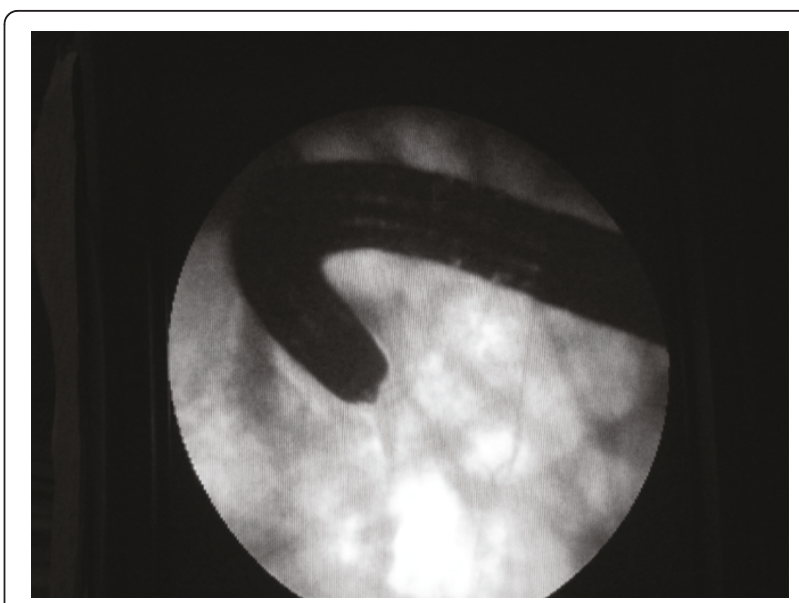

Figure 2 The 6 o'clock position

\section{Ethics}

Ethical clearance for the study was obtained from the Ethics Committee of the Faculty of Medicine, University of Kelaniya, Sri Lanka. Informed written consent was obtained from all patients.

\section{Statistics}

Sample size calculation was done on an assumption of $75 \%$ v $95 \%$ success at ileal intubation with the PP comp, and at $90 \%$ power this required a sample of 150 patients. The data was compared using Chi squared test and the statistical difference between the two groups will compared using the program SPSS 16.

\section{Results}

Two hundred and two consecutive patients were referred for Colonoscopy during the study period (Figure 3). Colonoscopy was performed on 150 patients [ 82 females, mean (SD) age 53 (16) years]. 75 patients were randomized for ileal intubation in the $\mathrm{PP}$ (prone position) and 75 patients in the LLP(left lateral position). The two groups were comparable for age, sex, indication for colonoscopy (Table 1). Overall, the ileum was successfully intubated in 145 (96\%) patients [74 (98.7\%) in the PP and71 (94.7\%) in the LLP] (Table 2). The median (Interquartile Range) ileal intubation time was12 (10) seconds in the PP and 87(82) seconds in the LLP $(\mathrm{p}<0.0001$; Mann-Whitney $\mathrm{U}$ test). The ileum was abnormal in 11 (7.5\%) patients: 6 in the PP group and 5 in the LLP group.

\section{Discussion}

We have shown that during colonoscopy, the prone 12 o'clock position gives a more direct approach to the ileo-caecal valve and, although the ileum was intubated in more than $90 \%$ of cases in both positions, significantly reduces ileal intubation time when compared to 


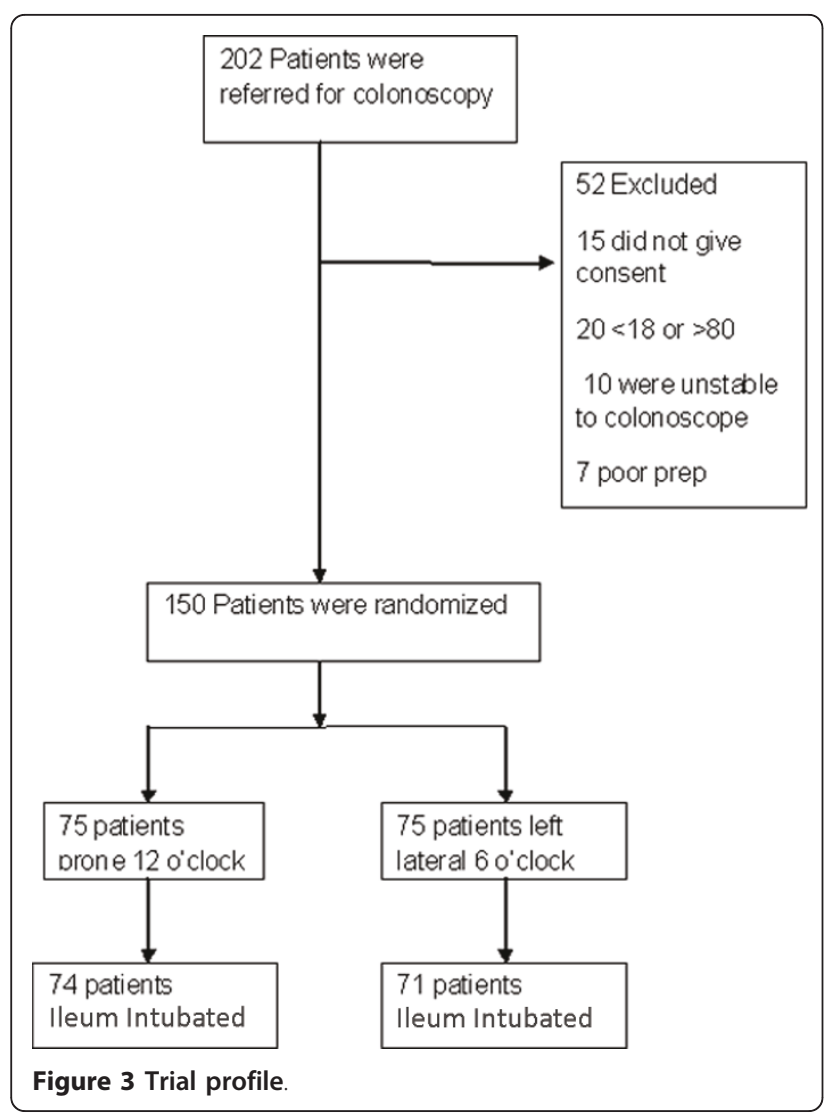

the standard left lateral 6 o'clock position. The reason for this is that in the prone 12 o'clock position, the axis of the tip of the colonoscope is the same as the ileocaecal valve (as clearly demonstrated during fluoroscopy). This makes entry into the ileocaecal valve much easier. The ileal abnormality rate was similar in both groups, and would therefore have not confounded our results.

Table 1 Demography and Indication for Colonoscopy

\begin{tabular}{lll}
\hline Variables & $\begin{array}{l}\text { Prone 12 } \\
(\mathbf{n}=\mathbf{7 5})\end{array}$ & $\begin{array}{l}\text { Left lateral } \\
(\mathbf{n}=\mathbf{7 5})\end{array}$ \\
\hline Mean age(Range) years & $50(18-80)$ & $55(18-80)$ \\
\hline Males:Females & $40: 35$ & $42: 33$ \\
\hline Diarrhoea & 8 & 5 \\
\hline Constipation & 8 & 12 \\
\hline Altered bowel habits & 19 & 18 \\
\hline Abdominal pain & 16 & 12 \\
\hline Iron deficiency Anaemia & 9 & 10 \\
\hline Per rectal bleeding & 3 & 6 \\
\hline IBD† & 6 & 8 \\
\hline Carcinoma of unknown primary & 3 & 1 \\
\hline Loss of weight or/and Loss of appetite & 3 & 3 \\
\hline †-Inflammatory Bowel Disease & &
\end{tabular}

Table 2 Ileal Intubation Time and Finding

\begin{tabular}{|c|c|c|c|}
\hline Variables & $\begin{array}{l}\text { Prone } \\
12 \\
(n=75)\end{array}$ & $\begin{array}{l}\text { Left } \\
\text { lateral } \\
(n=75)\end{array}$ & $\begin{array}{l}P \\
\text { Value }\end{array}$ \\
\hline $\begin{array}{l}\text { Median (inter quartile range) time taken } \\
\text { for ileal intubation (seconds) }\end{array}$ & $12(5-15)$ & $\begin{array}{l}87(18- \\
100)\end{array}$ & $\begin{array}{l}0.0001 \\
*\end{array}$ \\
\hline $\begin{array}{l}\text { Median (inter quartile range) time taken } \\
\text { for colonoscopy (seconds) }\end{array}$ & $\begin{array}{l}910 \\
(670- \\
1420)\end{array}$ & $\begin{array}{l}977 \\
(680- \\
1400)\end{array}$ & $0.89^{*}$ \\
\hline $\begin{array}{l}\text { lleal finding } \\
\text { Number of patients with ileitis }\end{array}$ & 6 & 5 & $0.75^{* *}$ \\
\hline
\end{tabular}

There are a few aspects of our study that warrant discussion. We did not assess other positions for ease of ileal intubation. However, we used the best position established by other studies and what is generally accepted as the best position (6 o'clock position) versus what we empirically thought and was also supported by fluoroscopy as was the best position (12 o'clock). Although our analysis did not take into account possible confounding factors such as the endoscopist, nurses and bowel preparation, we attempted to minimize these by having the same nursing team, two colonoscopists and using standard bowel preparation for all our patients during the study. The argument regarding the value of ileal intubation itself also warrants comment. Some studies have shown that only very few (1\%) patients who undergo ileoscopy have abnormalities in the ileum [5]. However, other studies including our own data show much higher rates of detection of ileal pathology $[3,6]$.

Although several previous studies have reported on the time taken for ileal intubation, such timings have not been standardized [6]. This has resulted in varying definitions of ileal intubation times which are not comparable, and the times reported range from seconds in some studies to more than ten minutes in some [7]. While no studies have clearly stated how to define ileal intubation time, it is assumed to be the time taken to maneuver the endoscope from the tip of the valve into the terminal ileum $[4,8]$. We felt that this does not give a true reflection of the difficulty of the procedure. We, therefore, defined it as the time taken for the tip of the colonoscope to be maneuvered from the mid-point of the caecum to entering the terminal ileum. Furthermore, we did not design our trial as a cross over study because once the ileum is intubated, the valve becomes patulous making the second intubation is easier [4]. Although the time difference between the two methods may not have much clinical significance (12 seconds vs 87 seconds) it may be significant for training purposes.

\section{Conclusion}

In conclusion, we recommend the prone 12 o'clock position for ileal intubation during colonoscopy as it is easier and takes less time. 


\section{Author details}

'Departments of Medicine, Faculty of Medicine, University of Kelaniya, Ragama, Sri Lanka. ${ }^{2}$ North Colombo Teaching Hospital, Ragama, Sri Lanka. ${ }^{3}$ Department of Pharmacology, Faculty of Medicine, University of Kelaniya, Ragama, Sri Lanka. ${ }^{4}$ Department of Public Health, Faculty of Medicine, University of Kelaniya, Ragama, Sri Lanka.

\section{Authors' contributions}

APDS and HJdS were involved in conceptualizing and writing the study. KSK $\mathrm{MN}$ and UK, were involved in colonoscopy. ASD was involved in the patient care. BSDPK was involved in data gathering. AP was involved in the statistical analysis. All authors read the manuscript and were involved in editing the final copy.

\section{Competing interests}

The authors declare that they have no competing interests.

Received: 25 April 2011 Accepted: 4 August 2011

Published: 4 August 2011

\section{References}

1. Borsh G, Schmidt G: Endoscopy of the terminal ileum: Diagnostic yield in 400 consecutive examinations. Dis Colon Rectum 1985, 28:499-501.

2. Harwood GC, Mattek NC, Holub JL, Peters D, Lieberman DA: Variation in practice of ileal intubation among diverse endoscopy settings:results from a national endoscopic database. Aliment Pharmocol Ther 2005, 22:571-8.

3. Seong HJ, Kwang JL, Yeong BK: Diagnostic value of terminal ileum intubation during colonoscopy. J Gastroenterol and Hepatol 2008, 23:51-5.

4. Ansari A, Soon SY, Saunders BP, Sanderson JD: A Prospective Study of The Feasibility of Ileoscopy at Colonoscopy. Scand J Gastroenterol 2003, 38:1185-7.

5. Kennedy G, Larson D, Wolff B, Winter D, Petersen B, Larson M: Routine ileal intubation during screening colonoscopy: a useful maneuver? Surg Endosc 2008, 22:2606-2608.

6. Wijewantha H, Wijesinghe NT, De Silva AP, Kumarasena RS, Dassanayake AS, Senanayake SM, Hewawasam SM, Pathmeswaran A, de Silva HJ: The usefulness of ileoscopy during colonoscopy. Gastrointes Endoscopy 2011, 73, No. 4S: AB340 (abstract).

7. Kundrotas LW, Clement DK, Kubik CM, Robinson AB, Wolfe PA: A prospective study of successful ileal intubation during routine colonoscopy. Gastrointes Endosc 1994, 40:544-6.

8. lacopini G, Frontespezi S, Vitale MA, Villotti G, Bella A, d'Alba L, De Cesare A, lacopini F: Routine ileoscopy at colonoscopy:a prospective evaluation of the learning curve and skill-keeping line. Gastrointest Endosc 2006, 63:250-256.

\section{Pre-publication history}

The pre-publication history for this paper can be accessed here: http://www.biomedcentral.com/1471-230X/11/89/prepub

doi:10.1186/1471-230X-11-89

Cite this article as: De Silva et al:: The prone 12 o'clock position reduces ileal intubation time during colonoscopy compared to the left lateral 6 o'clock (standard) position. BMC Gastroenterology 2011 11:89.

\section{Submit your next manuscript to BioMed Central and take full advantage of:}

- Convenient online submission

- Thorough peer review

- No space constraints or color figure charges

- Immediate publication on acceptance

- Inclusion in PubMed, CAS, Scopus and Google Scholar

- Research which is freely available for redistribution

Submit your manuscript at www.biomedcentral.com/submit
Biomed Central 